\title{
UN RECORRIDO POR LAS POLÍTICAS EDUCATIVAS EN TORNO A LA ENSEÑANZA DEL ESPAÑOL COMO LENGUA EXTRANJERA EN BRASIL
}

\author{
Carolina Paola Tramallino \\ Universidad Nacional de Rosario (Argentina) \\ carotramallino@gmail.com \\ Antonia Nilda Alves \\ Instituto Federal de Maranhão - IFMA (Brasil) \\ antonianilda@ifma.edu.br
}

Recibido: 27/05/2020 - Aprobado: 29/07/2020 - Publicado: 15/04/2021

DOI: doi.org/10.17533/udea.lyl.n79a08

\begin{abstract}
Resumen: Se muestra la vinculación entre la enseñanza de lenguas extranjeras y las políticas educativas en instituciones escolares brasileñas. Primero, se repasaron las políticas lingüísticas en Brasil aplicadas en la educación, especialmente en la enseñanza del español como lengua extranjera tras la sanción de la Ley 11.161/05. Se indagó, además, sobre el posicionamiento de otras lenguas extranjeras sobre el español, dada la necesidad de una lingua franca y la integración regional como un asunto de glotopolítica. Se examinó, finalmente, una experiencia educativa de cursos integrados en el Instituto Federal de Maranhão, reconociéndose la dimensión política en el lenguaje.
\end{abstract}

Palabras clave: glotopolítica; enseñanza; español; lengua extranjera; Brasil.

\section{AN OVERVIEW OF EDUCATIONAL POLICIES REGARDING THE TEACHING OF SPANISH AS A FOREIGN LANGUAGE IN BRAZIL}

\begin{abstract}
The link between the teaching of foreign languages and educational policies in Brazilian schools is shown. First, the language policies in Brazil applied in education were reviewed, especially in the teaching of Spanish as a foreign language after the passage of 11.161/05 Act. An inquiry about the positioning of other foreign languages over Spanish was also done, given the need for a lingua franca and regional integration as a matter of glottopolitics. Finally, an educational experience of integrated courses at the Federal Institute of Maranhão was examined, recognizing the political dimension in language.
\end{abstract}

Key words: glottopolitics; teaching; Spanish; foreign language; Brazil. 


\section{Introducción}

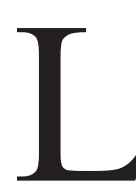

a finalidad de este artículo es mostrar la vinculación entre la enseñanza de lenguas extranjeras y su enfoque en las políticas educativas de instituciones escolares brasileñas. Para eso, se explicará cómo se

efectuaron las diferentes disposiciones sobre la enseñanza de lenguas extranjeras en Brasil, sobre todo en lo que respecta a la sanción de la Ley 11.161/05 conocida como Ley del español. De esta forma, la presente investigación se enfocó en las políticas educativas desde la perspectiva de las políticas lingüísticas como forma de comprender la formación de la identidad y el reconocimiento de la supremacía de la lengua portuguesa en Brasil, un país multicultural que tiene un solo idioma oficial.

En el primer apartado, se definirán las políticas educativas para luego mencionar las dificultades del sistema escolar brasileño a la hora de implementarlas. En el segundo apartado, se abordará el concepto de políticas lingüísticas como el conjunto de las acciones emprendidas en cuanto a la enseñanza del español como lengua extranjera en Brasil. Por último, se revisará la legislación vigente respecto a la enseñanza de idiomas, especialmente las concernientes a la obligatoriedad del español en la educación básica. Particularmente, se hará énfasis en los cursos integrados de formación técnica del Instituto Federal de Maranhão como una iniciativa de ampliación del acceso a la educación, para mostrar el reto que significa la enseñanza de lenguas extranjeras en el área técnica profesional.

\section{Las políticas educativas}

El concepto de las políticas educativas alude a las acciones que llevan a cabo los gobiernos en el ámbito de la educación. Forman parte del conjunto de las políticas públicas dirigidas a la sociedad. Como explicó Jakimiu (2016), toda política pública se crea para satisfacer la demanda de una realidad surgida a partir de la tensión generada en los diferentes segmentos de la sociedad.

Asimismo, cada política educativa apunta a un cambio en la educación, ya sea a través del currículo, o bien en las condiciones de acceso a la educación, de permanencia y también en la promoción de la igualdad, entre otras (Jakimiu, 2016). Dichas prácticas se concretizan en la cultura escolar a través de programas que son los mecanismos empleados para hacerlas efectivas y permitir que estas lleguen a las escuelas.

Respecto del concepto política, Rizvi y Lingard (2013) sostuvieron lo siguiente: «A lo largo de los años, se ha planteado una amplia variedad de definiciones, lo que indica que la política es un concepto polémico» (p. 26). Dicha polémica repercute en la toma de conciencia de los derechos y deberes políticos que posee cada ciudadano y en sus atribuciones sociales. Siguiendo a Pulido Chaves (2017): «La política pública aparece como resultado de un conjunto de negociaciones complejas determinadas por condiciones de tiempo, lugar y sujeto o, lo que es igual, dependen de correlaciones de fuerzas sociales determinadas» (p. 33).

Es importante destacar que, estas gestiones son fundamentales para la conducción de proyectos que intenten 
Un recorrido por las políticas educativas en torno a la enseñanza del español como lengua extranjera en Brasil solucionar problemas y para dar seguimiento a acciones requeridas en el ámbito educativo en lo que atañe al desarrollo de condiciones sociales, tecnológicas y de sanidad. En este sentido, Rizvi y Lingard (2013) plantearon que «la política educativa trata de lograr efectos en los externos dominios sociales, culturales y económicos en los que se podrían ver como resultados políticos» (p. 30).

En el caso de Brasil, los avances en la educación se establecieron a través de determinadas políticas públicas educativas, aunque todavía no se hayan resuelto algunas cuestiones cruciales, como es el caso del analfabetismo y la imposibilidad garantizar efectivamente el acceso de todos los estudiantes a la enseñanza básica y superior. Cabe aclarar que en Brasil la educación fundamental tiene una duración de nueve años, mientras que la enseñanza media dura tres años.

\subsection{Algunas dificultades en la aplicación de las políticas educativas en Brasil}

Durante los años 1980 y 1990 se incorporaron a la educación sectores más populares y la enseñanza básica logró expandirse al interior. La Ley 9394/96, conocida como la Ley de Directrices y Bases de la Educación Brasileña, fue sancionada en el gobierno de Fernando Henrique Cardoso, a través de la gestión del ministro de Educación, Paulo Renato. Aún hoy no se han resuelto algunas cuestiones elementales del ámbito educativo, como por ejemplo el problema del analfabetismo.

De manera análoga, a partir de los resultados de las evaluaciones nacionales — SAEB (Sistema de Avaliação da Educação Básica), ENADE (Exame Nacional do Desempenho dos Estudantes), e IDEB (Indices de Desenvolvimento da Educação Básica) — ${ }^{1}$ se observa que un gran porcentaje de alumnos —el 45,95\% en el quinto año y el 73,04 \% en el noveno año de la enseñanza básica — no sólo presenta dificultades en la lectura, sino que tampoco puede resolver operaciones elementales de matemáticas.

Por consiguiente, el desarrollo de las habilidades lingüísticas necesarias para el aprendizaje de una lengua extranjera resulta insuficiente, debido a las dificultades detectadas en las pruebas de comprensión de textos en lengua materna. De acuerdo con Jakimiu (2016): «No caso da Educação brasileira, o quadro situacional que revela as demandas educacionais é retratado pelos resultados expressos pelos índices obtidos por meio de avaliações, as quais tornam públicas as fragilidades da realidade educacional» (p. 3 ).

Igualmente, las evaluaciones como SINAES (Sistema de Nacional de Avaliação da Educação Superior) señalan un escaso rendimiento de los alumnos en los cursos de pregrado, tanto de los que están iniciando la carrera como también de los que egresan, principalmente en las provincias con menos recursos económicos del país, ubicadas en las regiones del norte y nordeste.

Con respecto al ingreso a la enseñanza universitaria, el acceso se realiza mediante la aprobación del examen vestibular. En 2010, surge el programa conocido como el Sistema de Selección Unificado, en el que las instituciones ofrecen cupos a candidatos que participan del Exame Nacional do Ensíno Médio (ENEM)² seleccionando a los

1. Estos sistemas de evaluación tienen como objetivo realizar un diagnóstico del aprendizaje en las escuelas, con el fin de garantizar los subsidios para implementar las políticas públicas educativas.

2. Prueba del Ministerio de Educación que evalúa a los alumnos egresados de la enseñanza media para clasificarlos antes de su ingreso a un curso de nivel superior. 
Un recorrido por las políticas educativas en torno a la enseñanza del español como lengua extranjera en Brasil postulantes con las mejores notas en las pruebas. Estos cambios surgen en el marco de iniciativas orientadas a ampliación del acceso a la educación superior, como el ProUni (2004), que concede cupos en instituciones privadas con o sin fines de lucro, a los estudiantes con bajos ingresos que hayan cursado la enseñanza media en la condición de becarios. (Atairo \& Camou, 2019). Si bien en los gobiernos progresistas hubo un intento de garantizar el acceso a la educación superior para todas las clases sociales y etnias a través de la política pública de cuotas para negros e indígenas, esto no fue suficiente.

\subsection{Las políticas lingüísticas: la lengua portuguesa como lengua oficial en Brasil}

Queda claro que toda política lingüística se vincula con las lenguas en uso de una determinada sociedad, demostrando así el poder económico del idioma oficial. En Brasil, la lengua portuguesa se impone como la lengua hegemónica y muchos hablantes creen que es la única en todo el país (Sousa \& Soares, 2014). Estos autores señalaron que hay un «olvido» de la situación plurilingüe en algunas regiones, como las del Centro-Oeste y Norte, principalmente en lo que atañe a la existencia de lenguas autóctonas que todavía se hablan en las comunidades nativas.

Aunque sea un país multiétnico, tanto de etnias autóctonas — indígenas - como extranjeras — colonizadores e inmigrantes - continúa constituyéndose como un país tendiente a poseer un solo idioma oficial: el portugués. Esta es la lengua de los colonizadores, teñida por los matices culturales de los nativos y de los extranjeros que llegaron al país, como, por ejemplo, esclavos africanos e inmigrantes europeos. Dicha mezcla, influenciada por diferentes culturas, como la de los colonizadores, esclavos e inmigrantes, además de los idiomas indígenas, convergió en la formación de la lengua portuguesa brasileña con una identidad propia.

Con respecto a la cuestión de la enseñanza de la lengua, la Sección iII de la Constitución, en el artículo 32 , inciso $3^{\circ}$, declara que la escolaridad fundamental regular será impartida en lengua portuguesa, garantizada a las comunidades indígenas en los procesos propios de enseñanza, además de sus lenguas originarias. (LDB, citado en Brandão, 2005).

\section{La diversidad lingüística}

Si bien el portugués es el idioma oficial de Brasil, no hay que olvidar que existen cerca de 274 lenguas indígenas en el país, que por no tener contacto con el portugués no logran ser reconocidas y estudiadas. Según el Censo $\mathrm{IBGE}^{3}$ de 2010, el país contaba con 896900 indígenas, miembros a su vez de 305 grupos étnicos, de los cuales el más grande es el tikuna, con 46 045, es decir, el 6,8 \% de la población indígena brasileña. Se presume que en la época en que llegaron los colonizadores había 1300 lenguas diferentes, que, por diversos motivos, como la mortalidad indígena y a la aculturación, se han perdido casi 1000 de esas lenguas (Gaspar, 2011).

3. IGBE (Instituto Brasileño de Geografía y Estadística). 
Un recorrido por las políticas educativas en torno a la enseñanza del español como lengua extranjera en Brasil

En cuanto a la forma de clasificar los idiomas indígenas, en la actualidad se prefiere agruparlos en familias que, a su vez, se reúnen en troncos lingüísticos, teniendo en cuenta sus similitudes y diferencias. De esta forma, se los divide en dos grandes troncos de lenguas indígenas, que son tupi y macro-jê, además de las familias de lenguas que, debido a que no poseen grados de semejanza suficientes, no pueden agruparse en troncos ${ }^{4}$. El tronco de tupi consta de las siguientes familias genéticas: tupi-guaraní, monde, tupari, juruna, mundurukú y ramarána, las cuales a su vez también incluyen tres idiomas aislados: awetí, sateré-mawé y puruborá. Siguiendo a Gaspar (2009), estas lenguas se hablan en varias regiones de Brasil, además de otros países de América del Sur, como Bolivia, Perú, Venezuela, Guayana Francesa, Colombia, Paraguay y Argentina. Todas las otras familias en el tronco de tupi están ubicadas en Brasil, en el sur del río Amazonas. El tronco macro-jê, por su parte, tiene cinco familias genéticas: jê, bororo, botocudo, karajá y maxakalí, además de cuatro idiomas: guató, ofayé, rikbaktsá y yathê o fulniô.

En la constitución de 1988, se busca un reconocimiento de las lenguas originarias y garantizar el derecho a la educación en sus lenguas maternas, como forma de mantener viva la cultura lingüística de los pueblos indígenas. Como afirma Londres Fonseca (2008) «A formação de educadores aptos a ministrar uma educação básica bilíngüe tem sido um dos eixos centrais dessa política, [...], ação que certamente contribuirá para a sobrevivência das cerca de duzentas línguas indígenas ainda faladas hoje no Brasil» (p.1).

\section{La legislación sobre la enseñanza de lenguas extranjeras en Brasil}

El presente trabajo se inscribe en el área de la glotopolítica, un campo de estudio definido como el «planeamiento lingüístico» tendiente a incidir en el espacio social del lenguaje, al responder a las distintas demandas y convocar la participación de las instancias sociales involucradas (Arnoux, 2014).

Se hará énfasis especialmente en una problemática de tal tipo surgida en los últimos años: la amenaza que recae sobre el español y el portugués ante los requerimientos de integración regional y el posicionamiento de otras lenguas como medios para la comunicación ante la necesidad de una lengua global (Wright, 2003). En ese sentido, el concepto de integración regional es explicado y desarrollado por Arnoux (2008) en su artículo sobre los desplazamientos significativos del III Congreso de la Lengua Española, en el cual concluyó que la diversidad lingüística debe ser comprendida en relación con el proceso de globalización que requiere de integraciones regionales. Esa lengua común — el español—, que había servido como herramienta de unificación en la construcción de los estados nacionales, se ve amenazada por los acuerdos regionales y por la emergencia de lenguas que se erigen como «principales», como el caso del inglés, dado el contexto de la globalización.-En este sentido, tal como explicó Lorencena Souza (2017), surge el temor de que se debilite la hegemonía de la lengua portuguesa, impuesta por la fuerza frente a la diversidad lingüística del Brasil. Dicho temor se comprueba también en el tratamiento que la asignatura de Lengua Extranjera ha recibido por parte del gobierno. Ante este panorama, se mostrará en los apartados siguientes cómo a lo largo de la historia de la educación en Brasil la enseñanza del

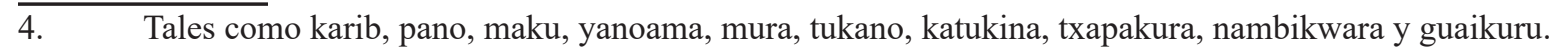


Un recorrido por las políticas educativas en torno a la enseñanza del español como lengua extranjera en Brasil español oscila entre el elevarse y el declinar de acuerdo con los intereses de las relaciones políticas y económicas internacionales.

\subsection{Los cambios en el diseño curricular}

A comienzos del siglo xx, las lenguas extranjeras modernas más importantes, como el español, el inglés y el francés se integraron al diseño curricular junto al latín y el griego. Inicialmente, en 1941, se creó el curso de Letras Neolatinas en la Universidad Federal de Río de Janeiro, con los cursos de Español, Francés e Italiano. Un año después, en 1942 se realizó la Reforma Capanema, en la cual se incluyó al español en el diseño curricular de la enseñanza secundaria. Así, por medio del Decreto n. ${ }^{\circ} 4244 / 42$, en su artículo 12 , se garantizaría a la lengua española la misma carga horaria que para el inglés: «As disciplinas pertinentes ao ensino dos cursos clássico e científico são as seguintes: Línguas: 1. Português. 2. Latim. 3. Grego 4. Francês. 5. Inglês. 6. Espanhol» (Decreto n. ${ }^{\circ} 4244 / 42$, p. 4). No obstante, dicha legislación solo tuvo vigencia por menos de veinte años.

En la segunda mitad del siglo xx, el inglés se torna como la lengua franca, debido a la hegemonía económica de los EE UU después de la Segunda Guerra Mundial. Como afirmó Sedycias (2005), en dicho período el español perdió su lugar de importancia, pero volvió a cobrar visibilidad en la educación brasileña con la sanción de la Ley 11.161/05 o Ley del español en 2005, bajo el gobierno de Luís Inácio Lula da Silva. Sin embargo, el espacio central duraría poco más de una década, ya que en 2016 el presidente Michel Temer revocó la misma y el idioma quedó ubicado, de esta forma, como una lengua de menor importancia respecto del inglés.

A partir de los años 90, la lengua española asumió un lugar primordial impulsado por el Acuerdo de Asunción y el surgimiento del MERCOSUR. Por tal motivo, Sedycias (2005) organizó el primer libro con varios artículos sobre la enseñanza de español en Brasil, titulado O ensino de espanhol no Brasil: passado, presente e futuro, en el cual se destaca la importancia del aprendizaje de dicha lengua y los motivos por los cuales los brasileños deberían aprenderla. También contiene algunos capítulos con un enfoque metodológico respecto del proceso de enseñanza-aprendizaje del idioma.

En cuanto a las normativas que orientan la enseñanza de lenguas extranjeras se encuentran las Directrizes e Bases da Educação Brasileira (LDB) (1996), los Parámetros Curriculares Nacionais (PCN) (1998), las Orientacões Curriculares Nacionais para o Ensino Médio (OCN) (2006), y las Concepções e Directrizes dos Institutos Federales (IF) (2008). Previamente, hasta 1996 regía la LDB, en la cual se definía la obligatoriedad de la enseñanza de por lo menos dos lenguas extranjeras.

Con respecto a las directrices metodológicas, en las OCN se plasmó cómo debía ser la enseñanza de lenguas extranjeras y el papel educativo del aprendizaje de cada uno de estos idiomas. En dichas disposiciones se establecía que lo fundamental era abordar el conocimiento de otra lengua desde un enfoque cultural, no solo como forma de desarrollar las competencias comunicativas orales y escritas, sino también como constituyente de significados, conocimientos y valores. 
Un recorrido por las políticas educativas en torno a la enseñanza del español como lengua extranjera en Brasil

\subsection{La concepción del lenguaje desde los Parámetros Curriculares Nacionales}

Los Parámetros Curriculares Nacionales (PCN) (1998) conceptuaron al lenguaje como la capacidad que poseen los humanos para producir sentidos a través de un sistema arbitrario de representaciones y de sus experiencias vividas en la sociedad: «A linguagem é considerada aqui como a capacidade humana de articular significados coletivos e compartilhá-los, em sistema arbitrários de representação que variam de acordo com as necessidades e experiências da vida em sociedade» (p. 5).

A partir de dicha visión, el objeto principal de la comunicación era que los individuos interactuaran en el espacio social en donde habitaban. En ese sentido, en los objetivos generales de los PCN se definía que el alumno debía ser capaz de comunicarse a través de diferentes lenguajes e interpretar y disfrutar de las producciones culturales en el ámbito público y privado. (PCN, 1998).

Por otra parte, se reconocía la importancia del aprendizaje de varias lenguas, subrayando el hecho de poner en práctica políticas de pluralismo lingüístico en las escuelas:

Se essas duas línguas são tão importantes no mundo globalizado, muitos são os fatores que devem ser levados em consideração no momento de escolher-se a[s] línguas estrangeira[s] que a escola ofertará aos estudantes, como podem ser as características sociais, culturais e históricas da região onde se dará o estudo (PCN, 1998, p. 27).

Sin embargo, a pesar del énfasis colocado en esta cuestión, se aceptaron los problemas surgidos con respecto a la inclusión de más de un idioma extranjero en el currículo, principalmente en las escuelas del Estado:

Além da carência de professores com formação adequada e o fato de que, salvo exceções, a língua estrangeira predominante no currículo ser o inglês, reduziu muito o interesse pela aprendizagem de outros línguas estrangeiras e consequentemente formação de professores de outros idiomas. Portanto, mesmo quando a escola manifesta o desejo de incluir outra língua estrangeira, esbarra na grande dificuldade de não encontrar profissionais qualificados (PCN, 1998, p. 25).

Las causas de estas dificultades radicarían no sólo en la ausencia de profesores calificados que contaran con capacitación específica en lengua española, sino también en el número de asignaturas presentes en el currículo de las escuelas.

Luego, la primera década de este siglo fue de gran significación en la formación de profesores de lengua española en Brasil gracias a la Ley 11.161/05 o la Ley del español, la cual estableció la obligatoriedad de su enseñanza en las escuelas públicas brasileñas. Por este motivo, las universidades estatales y privadas ofrecieron el curso de Letras con habilitación en lengua española para la formación de profesores, como cumplimiento de la mencionada legislación. Además, las instituciones de educación superior contaban con cinco años para capacitar a profesores con formación universitaria que pudieran dar clases de español en el nivel secundario. Sin embargo, el inconveniente que se presentaba era alcanzar la cantidad de docentes necesarios para atender a todas las escuelas de las 27 unidades federativas de Brasil, especialmente en las ciudades más lejanas del interior. Para solucionarlo, se necesitaban 230000 docentes de español, pero por ese entonces solo había 6600 impartiendo clases en escuelas públicas y privadas brasileñas (Sánchez Cabezudo, 2005). Así, se empezaron a tomar medidas, como la capacitación a los profesores y la apertura de varias sedes del Instituto Cervantes en Brasil. No obstante, 
Un recorrido por las políticas educativas en torno a la enseñanza del español como lengua extranjera en Brasil la cantidad de docentes calificados resultó insuficiente frente a la gran demanda requerida a causa de la extensa dimensión territorial a cubrir. De este modo, con la revocación de esta ordenanza en 2016 por parte del presidente Michel Temer, la enseñanza de español pasó a ser opcional, es decir, como una segunda posibilidad de idioma para los estudiantes, luego del inglés.

Siguiendo a Carvalho (2014), a lo largo del tiempo se intentó introducir el español en el currículo del sistema educativo brasileño, y aún transcurridos más de diez años de la aprobación de la Ley 11.161/05 o Ley del español, «la enseñanza de español todavía no encontró su compás» (p. 26). Esto se debe tanto a las trabas burocráticas como al desconocimiento de la normativa por parte de las directivas educativas, circunstancias que impidieron la incorporación de la enseñanza de la lengua española en la educación pública de Brasil.

Al respecto, cabe aclarar que algunos factores considerados a la hora de la incluir un idioma extranjero en el currículo son los históricos, económicos y sociales. Frente a la decisión de haber implantado el inglés como la primera lengua extranjera en la enseñanza, influyó la supremacía de los Estados Unidos en el mundo y la dependencia económica de Brasil respecto de aquel. En este sentido, resulta pertinente el punto de vista expuesto por Lorencena Souza (2017), quien afirmó que el hecho de determinar una única lengua como disciplina obligatoria da cuenta de la desvinculación de cualquier objetivo multicultural en la enseñanza, centrándose únicamente en su carácter funcional.

\section{La incidencia de la creación de los Institutos Federales}

Los Institutos Federales (IF) cuentan con poco más de una década de trayectoria y forman parte de las políticas educativas impulsadas por el Gobierno Federal a través del Ministério da Educação (MEC) y su Plano de Desenvolvimento da Educação (PDE) (IFRN, 2008). Estos centros educativos habían surgido como escuelas de «Aprendizes Artífices», con la finalidad de capacitar profesionalmente a la clase proletaria a través del Decreto 7.566, bajo el gobierno de Nilo Peçanha en 1909, creándose así una unidad de enseñanza en cada capital del país. Años después, el objetivo de su reinstauración en 2009 bajo el nombre de Institutos Federales de Educación, Ciencia y Tecnología, es el de contribuir al desarrollo mediante la capacitación profesional y además disminuir las desigualdades sociales, cumpliendo así con una función social: «O que se cumpre matiza definitivamente a função social dos Institutos Federais. Assim, é na definição de sentidos que devem ficar estabelecidas a natureza e a singularidade dessas instituições» (IFRN, 2008 p. 5). Estos institutos asumen como finalidad ofrecer cursos relacionados con las necesidades particulares de los centros poblados para aumentar la cualificación profesional y así promover el desarrollo económico, social y cultural de cada región geográfica:

O foco dos Institutos Federais será a justiça social, a eqüidade, a competitividade econômica e a geração de novas tecnologias. Responderão, de forma ágil e eficaz, às demandas crescentes por formação profissional, por difusão de conhecimentos científicos e tecnológicos e de suporte aos arranjos produtivos locais (IFRN, 2008 p. 9).

A partir de este propósito, es la propia comunidad escolar la que elige su vocación profesional, en concordancia con las actividades existentes en cada localidad. Por ejemplo, el curso de Análisis Químicos es seleccionado por 
Un recorrido por las políticas educativas en torno a la enseñanza del español como lengua extranjera en Brasil una población de producción de biocombustibles, mientras que el de Agroindustria es elegido en las regiones dedicadas a la producción de lácteos y cárnicos. La implantación de estos programas se hace en cooperación con los estados y municipios, distribuyendo la oferta de cursos en diferentes modalidades de enseñanza que abarcan la educación básica secundaria, la técnica y la educación para adultos. Además, apoya la titulación en posgrados, basándose en la premisa de que el profesional técnico debe mantenerse en constante formación.

Los IF, por otra parte, ofrecen educación pública en cuatro modalidades de enseñanza, además de la destinada a adultos, basada en una práctica educativa humanística-técnica-científica: 1. Modalidad Integrada: para alumnos que hayan terminado la enseñanza fundamental con acceso a la última etapa de la educación básica integrada a una habilitación profesional técnica de nivel medio, cuya duración es de tres años. 2. Modalidad Subsecuente: destinada exclusivamente al estudiante que ya ha concluido la enseñanza media, con una duración de dos años. 3 . Modalidad Concomitante: dirigida al alumno que pertenece a otra institución educativa, por lo que solo cursará las disciplinas del núcleo técnico profesional, con tres años de duración. 4. Modalidad Superior: contempla Cursos Tecnológicos y Licenciaturas para quienes hayan concluido la enseñanza media, con una permanencia de tres años para los primeros y de cuatro para las segundas. 5. Educación de Jóvenes y Adultos: referente a una educación profesional para adultos — a partir de los 18 años_ que no hayan finalizado la enseñanza media.

En consecuencia, la problemática que se presenta en el campo de la educación básica y técnica profesional se plantea en el siguiente interrogante: ¿Cómo vincular los contenidos lingüísticos y culturales que poseen una base común con la modalidad técnica, sin dejar de lado el contenido específico laboral y su práctica, en los cursos de diferente actuación profesional? En este sentido, el artículo 26 de la LDB considera la importancia de una base

curricular común que debe ser complementada con contenidos que tengan en cuenta rasgos regionales y locales de la sociedad, de la cultura, de la economía y del cliente (LDB, 1996). Es interesante destacar que, además, la LDB señala que en la parte diversificada del currículo de la enseñanza fundamental deberá ser incluida por lo menos una lengua extranjera moderna de acuerdo con la necesidad de la comunidad y de responsabilidad de la institución (LDB, 1996).

\subsection{Los cursos integrados en el Instituto Federal de Maranhão}

Los cursos ofrecidos en el Instituto Federal de Maranhão (IFMA) tienen como eje la enseñanza técnica profesional para estudiantes que hayan concluido la educación básica e implican una instrucción distinta, por tratarse de una modalidad diferenciada dentro de la educación básica. Entre los programas que ofrecen se encuentran: Acuicultura, Agropecuaria, Agroindustria y Medio Ambiente.

Con respecto a los cursos de idiomas extranjeros dentro de los programas ofrecidos por el IF, el de Español se había impartido en base a la Ley11.161/05 o Ley del español durante diez años hasta 2016, cuando fue derogada por el gobierno de Michel Temer. Desde el inicio, hubo una expansión de la red, como forma de aproximar la educación a las poblaciones de regiones con menos recursos. Por este motivo, se ofrecen los cursos de Español solo 
Un recorrido por las políticas educativas en torno a la enseñanza del español como lengua extranjera en Brasil en los campus de Monte Castelo, Maracanã, Centro Histórico, Alcântara, Zé Doca y Barreirinhas. Actualmente, en Maranhão, se estima que hay en la actualidad aproximadamente 230 profesores de español en activo, distribuidos en los 217 municipios de dicho estado.

Por otra parte, las dificultades para alcanzar resultados positivos respecto de la implementación de la enseñanza de una lengua extranjera en los IF responden a varios factores. En primer lugar, la disciplina lingüística está fuertemente condicionada a cuestiones político-económicas, es decir, depende del presupuesto de cada instituto, de la cantidad de horas programadas para el idioma extranjero y del apoyo del gobierno estatal para poder impartir los cursos. Anteriormente y como muestra, se permitía únicamente la enseñanza del inglés bajo los gobiernos militares. En segundo lugar, no existen normativas vigentes para la enseñanza de idiomas extranjeros en los institutos técnicos; frente a esto, los diseños curriculares que implementan los IF para la enseñanza de lenguas extranjeras son los mismos que rigen para la enseñanza básica de nivel medio. En tercer lugar, la carga horaria destinada a las clases de lenguas extranjeras dentro del currículo del IFMA no es ecuánime 5 , ya que varía de acuerdo al curso impartido y a la cantidad de profesores existentes tanto para enseñar español como inglés. En cuarto lugar, los materiales didácticos no están adecuados a la realidad de los cursos dentro del eje de formación básica y profesional, ni mucho menos a la diversidad de cada región geográfica. Los manuales que se emplean son los del Programa Nacional do Livro e do Material Didático (PNLD), del mismo modo que en la enseñanza básica de las escuelas estatales que no están integradas a la educación técnica.

Por otra parte, se debe considerar que los factores motivacionales también pueden contribuir a un mejor aprendizaje. Por eso, la enseñanza requiere de posturas diferentes por parte de gestores y profesores en el diseño curricular de los cursos, para lograr el éxito en el desarrollo de las habilidades lingüísticas de los alumnos. Sin embargo, el principal inconveniente radica en que la mayoría de los estudiantes de los cursos integrados no ha estudiado antes una lengua extranjera y esto dificulta el interés y el desarrollo de la adquisición. Dicho problema se debe a que los alumnos egresados de las escuelas públicas municipales no han tenido contacto con el español, mientras que los que provienen de escuelas privadas sí han asistido a clases de español como lengua extranjera a lo largo de su ciclo escolar. Frente a esto, se nota una diferencia de nivel bastante acentuada entre los aspirantes a los cursos integrados. De este modo, la integración tardía de los cursos de español en el currículo de la enseñanza media dificulta el dominio de la lengua por parte de los estudiantes.

\section{Consideraciones finales}

Las cuestiones educativas brasileñas revisten gran complejidad a causa de las diferencias regionales, las situaciones sociales y económicas. La enorme diversidad lingüística y la imposición del portugués como lengua oficial impartida en las escuelas es uno de los factores que tiene como consecuencia un alto índice de analfabetismo

5. Las escuelas públicas deciden internamente la intensidad horaria destinada a los cursos de lenguas extranjeras, los cuales se pueden tomar entre 20 y 60 horas por semestre. En las escuelas privadas, por otra parte, se dedican 80 horas al año a los idiomas extranjeros. 
Un recorrido por las políticas educativas en torno a la enseñanza del español como lengua extranjera en Brasil y de escolarización incompleta. A pesar de los avances para fortalecer la educación primaria y secundaria en las últimas décadas, la proporción de jóvenes con baja educación sigue siendo preocupante, pues casi el $30 \%$ de los brasileños entre 18 y 25 años ni siquiera han cumplido con ocho años de estudios. Además, se debe tener en cuenta que el país posee la quinta población juvenil más grande del mundo, de los cuales apenas el $50 \%$ está estudiando, y de estos, el 56 \% presenta un retraso de edad con respecto a su grado de escolaridad (IFRN, 2008).

Aunque con gobiernos más atentos a la valorización de la cultura latinoamericana o interesados en un posible mercado económico integrado en América del Sur hayan intentado incluir al español en el diseño curricular, en las escuelas regulares su enseñanza sigue siendo escasa. Las consecuencias de esto son que los alumnos cuenten con bajos niveles de suficiencia frente a los requeridos en ninguno de los dos idiomas extranjeros —inglés y español—, tanto en las escuelas públicas como en las privadas, lo que se visualiza en los resultados de los exámenes ENEM y en los exámenes de ingreso de a las universidades. En la versión de dicho examen en 2019, en el estado de Maranhão, sobre un total de 172740 aprendientes que lo presentaron, solo el 3,78 \% obtuvo una calificación mayor a 600 de los 1000 puntos establecidos en el área de «Lenguaje, códigos y sus tecnologías». Mientras tanto, el $88 \%$ de los jóvenes obtuvo entre 400 y 600 puntos, sin alcanzar el puntaje necesario para la aprobación de la prueba en dicha área. En cuanto a los aprendientes de IFMA, solo el 4,91\% de ellos pudo conseguir un cupo en las universidades para el 2018. En el último año, la media de escolares de estos institutos obtuvo un puntaje de 514 de 1000 puntos, muy por debajo de la calificación mínima requerida. ${ }^{6}$

Así pues, para el alumno egresado de la educación secundaria desarrolle fluidez en un idioma extranjero es necesario que realice un curso en un instituto de idiomas privado para complementar los estudios de las escuelas regulares. Al respecto, resulta pertinente remitirse a la percepción de Varela (2008), al afirmar que en el campo del español como lengua extranjera son las empresas e instituciones educativas no formales las que propician cursos y capacitaciones, lo que a su vez deja un amplio espacio para la iniciativa educativa privada.

Por lo expuesto a lo largo de este artículo, puede notarse que el intento de expandir la enseñanza del español en las instituciones escolares brasileñas a partir de la sanción de la Ley 11.161/05 o Ley del español no prosperó, ya que fue revocada en 2016. La mayoría de los colegios privados eliminó el español como una forma de reducir costos y despidió a los profesores. En cuanto a las escuelas públicas se refiere, todavía no existe una determinación clara sobre su permanencia. Por otra parte, en los cursos integrados de IFMA en las sedes São Luis y Maracaná, sus estudiantes tienen cursos de lenguas extranjeras desde el primer al tercer año de estudios, con una intensidad horaria de 40 horas por semestre. La mayoría de dichos centros incluye en sus programas cursos de un solo idioma extranjero, como es el caso del curso de Acuicultura y Agropecuaria, los cuales ofrecen solo español, o el de Medio Ambiente, en el cual se imparte solo inglés. Únicamente el programa de Agroindustria tiene la opción de las dos lenguas: español e inglés.

Históricamente, la presencia del español fue admitida o rechazada por circunstancias políticas. Mientras que se le dio importancia a la lengua española bajo los gobiernos progresistas, en los mandos neoliberales se

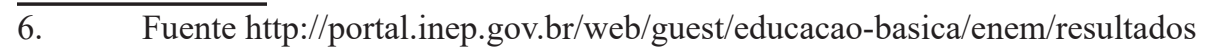


Un recorrido por las políticas educativas en torno a la enseñanza del español como lengua extranjera en Brasil priorizó al inglés como lengua franca, con la mirada puesta hacia la satisfacción de los intereses del imperialismo norteamericano. Por esto se debe a que actualmente, el idioma español se ubica en un lugar minoritario dentro del currículo, lo que explica que su enseñanza, según Lorencena Souza (2017) «está en extinción, hecho comprobado por el gran número de profesores que han perdido sus trabajos» (p. 11). En consecuencia, se considera que lograr el éxito en el aprendizaje de una segunda lengua en la enseñanza básica brasileña se constituye como una tarea muy difícil, por lo que se cree conveniente que se imparta solo en la educación secundaria y superior, o bien considerar para la enseñanza básica qué posibilidad de concreción real de dicha iniciativa posee cada estado y más aún cada escuela, de acuerdo a la situación que presente, la infraestructura con la que cuenta y la cantidad de docentes de lengua española calificados existentes en las regiones.

Por otra parte, se propone al IFMA como una institución pionera en educación integrada, que participa en programas de intercambio con varios países hispanohablantes. La inclusión de los cursos de lengua española como idioma extranjero es una propuesta innovadora y necesaria para los estudiantes, quienes deben insertarse en la sociedad de la información y del conocimiento dentro de un mundo globalizado. Sería propicio que en los años correspondientes a la enseñanza secundaria y superior de los cursos integrados se pudiera elegir, al igual que se elige el ciclo profesional según la actividad económica de la localidad, la lengua extranjera que se quiere estudiar, o bien, ofrecer tanto inglés como español, y no seguir limitando el plan de estudios a los cursos en un solo idioma. Se considera que ambas lenguas son necesarias para la formación de un profesional calificado técnicamente, quien debe contar con las habilidades lingüísticas necesarias a la hora de ejercer su carrera con ética, competencia y responsabilidad, pero, sobre todo, respetando tanto su cultura como otras culturas.

Cabe aclarar que la lengua, así como la música, el arte culinario, las indumentarias, la religión, la danza y las fiestas, son rasgos culturales fundamentales en la formación de la identidad social colectiva. Brasil es un país de dimensiones continentales, posee variaciones lingüísticas a causa de su colonización, de los procesos inmigratorios y de las zonas de frontera. Por ello, las políticas lingüísticas son necesarias para valorar y mantener viva la tradición de los diferentes pueblos que construyeron la historia de esta nación y la volvieron más rica y diversa. La imposición del inglés como único idioma extranjero sin que quede espacio para otras lenguas significa un avasallamiento contra el pluralismo lingüístico y la riqueza cultural del país. Sin embargo, se debe tener en cuenta que la enseñanza de idiomas no escapa a las decisiones del poder político vigente, el cual finalmente determina la elección de las lenguas que deberán o no formar parte del diseño curricular escolar. 
Un recorrido por las políticas educativas en torno a la enseñanza del español como lengua extranjera en Brasil Referencias bibliográficas

1. Araújo, C. M. de (2010) O Ensino de espanhol no Brasil: história de um processo em construção. http://www. apeesp.com.br/web/ciplom/Arquivos/artigos/pdf/catya-araujo-amanda-montanez

2. Arnoux, E. N. de (2008) «La lengua es la patria», «nuestra lengua es mestiza» y «el español es americano»: desplazamientos significativos en el III Congreso de la Lengua Española. En S. Hofmann, (Ed.), Más allá de la nación. Medios, espacios y nuevas comunidades imaginadas. (pp. 16-32). Berlín: Edition Tranvía.

3. Arnoux, E. N. de \& S. Nothstein (Eds.). (2014). Temas de glotopolítica. Integración regional sudamericana y panhispanismo. Buenos Aires: Biblos.

4. Atairo, D. \& Camou, A. (2019) Cogobierno y gratuidad em las universidades latinoamericanas. En Villanueva, E. (Comp.) La conquista de un derecho. Reflexiones latinoamericanas a 70 años de la gratuidad universitaria en Argentina. http://biblioteca.clacso.edu.ar/clacso/se/20191122115654/Gratuidad-universitaria.pdf

5. Brandão, C. (2005). LDB Passo a Passo: Lei de Diretrizes e Bases da Educação Nacional Lei Nº $9.394 / 96$ Comentada por Artigo por Artigo. São Paulo: Avercamp Educação.

6. Carvalho, J. (2014). Contrates e reflexões sobre o ensino de espanhol em escolas públicas do DF: uma visão real acerca da implantação da lei 11.161/2005. 2014. XVIII, 249 f., il. Dissertação (Mestrado em Linguística Aplicada). Universidade de Brasília, Brasília, 2014.

7. Decreto Lein. ${ }^{\circ}$ 4244/42 (1942). Câmara dos Deputados. https://www2 .camara.leg.br/legin/fed/declei/1940-1949/ decreto-lei-4244-9-abril-1942-414155-133712-pe.html

8. Gaspar, L. (2011). Línguas indígenas no Brasil. Pesquisa Escolar Online. Recife: Fundação Joaquim Nabuco. http://basilio.fundaj.gov.br/pesquisaescolar/

9. Gomes, V., Machado Taylor, M. \& Saraiva, E. (2018). O ensino superior no Brasil: breve histórico e caracterização. Ciência \& Trópico, 42(1), 106-129. https://fundaj.emnuvens.com.br/CIC/article/view/1647

10. Instituto Federal de Educaçâo, Ciếncia e Tecnologia - [IFRN] (2008). Concepção e diretrizes. Ministério da Educação. https://portal.ifrn.edu.br/institucional/normas-e-leis/concepcao-e-diretrizes-dos-institutos.pdf/view

11. Jakimiu, V. C. L. (2016). Consideraciones acerca do Campo disciplinar das políticas educacionais. Revista de Estudios Teóricos y Epistemológicos en Política Educativa, 1(2). 211-229. http://www.nodal.am/wp-content/ uploads/2017/03/52-293-2-PB.pdf

12. Londres Fonseca, M. C. (2008) Diversidad e linguística no Brasil: considerações sobre uma proposta de política en Patrimônio, Revista electrônica do Iphan. http://www.labjor.unicamp.br/patrimonio/materia.php?id=215

13. Lorencena Souza, H. (2017) La reforma de la enseñanza media y la muerte de la pluralidad lingüística en la educación brasileña. Revista Digital de Políticas Lingüísticas, 9(9). https://revistas.unc.edu.ar/index.php/RDPL/ article/view/19028

14. Orientações Curriculares para o Ensino Médio (2006). Vol. 1: Linguagens Códigos e Suas Tecnologias. http:// portal.mec.gov.br/seb/arquivos/pdf/book_volume_01_internet.pdf 
Un recorrido por las políticas educativas en torno a la enseñanza del español como lengua extranjera en Brasil 15. Orientações Educacionais Complementares aos Parâmetros Curriculares Nacionais (1998). Parâmetros Curriculares Nacionais para o Ensino Médio [PCN]. http://portal.mec.gov.br/seb/arquivos/pdf/linguagens02.pdf 16. Pulido Chaves, O. (2017) Política pública y política educativa: una reflexión sobre el contexto. Revista Educación y Ciudad, 33, 13-28. https://doi.org/10.36737/01230425.v0.n33.2017

17. Rizvi, F. \& Lingard, B. (2013). Políticas educativas en un mundo globalizado. Madrid: Morata.

18. Sanchez Cabezudo, F. (2005) El español en Brasil. https://cvc.cervantes.es/lengua/anuario/anuario_06-07/ pdf/paises_37.pdf

19. Sedycias, J. (2005). O ensino de espanhol no Brasil: passado, presente e futuro. São Paulo: Parábola Editora. 20. Sousa, S. T. de \& Soares, M. (2014). Um estudo sobre política linguística no Brasil. Revista de Letras, 33(1), 102-112. http://www.repositorio.ufc.br/bitstream/riufc/15948/1/2014_art_sctsousamesoares.pdf

21. Varela, L. (2008) La cuestión lingüística en el Mercosur. El Castellano. http://www.elcastellano.org/ns/ edicion/2008/marzo/mercosur.html

22. Wright, S. (2003). Language in a Post-National Era: Hegemony or Transcendence? In Language Policy and Language Planning: From Nationalism to Globalization, Part 2. New York: Macmillan. (Trad. de Paulina Bettendorff). 